\title{
FURTHER OBSERVATIONS ON ESCHERICHIA COLI ENTEROTOXINS WITH PARTICULAR REGARD TO THOSE PRODUCED BY ATYPICAL PIGLET STRAINS AND BY CALF AND LAMB STRAINS: THE TRANSMIS- SIBLE NATURE OF THESE ENTEROTOXINS AND OF A K ANTIGEN POSSESSED BY CALF AND LAMB STRAINS
}

\author{
H. Williams Smith* and Margaret A. Linggood \\ Animal Health Trust, Stock, Essex
}

SEver AL investigators (Moon, Sorensen and Sautter, 1966; Gyles and Barnum, 1967; Smith and Halls, 1967a; Nielsen and Sautter, 1968) have found the ligated-intestine test to be a reliable method of identifying enteropathogenic strains of Escherichia coli of porcine origin; pigs of various ages were used in these studies. Smith and Halls (1967a) observed that these strains also dilated ligated segments of calf and lamb intestine, that calf and lamb enteropathogenic strains dilated calf and lamb intestine but not pig intestine and that human enteropathogenic strains failed to dilate the intestine of all three species. Recently, Moon and Whipp (1970) reported three porcine strains of E. coli that consistently dilated ligated intestinal segments of piglets less than $1 \mathrm{wk}$ old, but not those of older pigs. We have confirmed their observation and have also found an additional strain that behaves similarly. We decided therefore to re-examine the susceptibility of ligated intestine of different animal species to strains of $E$. coli of different origins and to compare the enterotoxin produced by the four atypical pig strains with that produced by the majority of porcine enteropathogenic strains which dilated ligated intestinal segments of pigs of all ages. In some strains, this enterotoxin has been shown to be controlled by a transmissible plasmid (Smith and Halls, 1968) and to exist in two forms in culture media, one heat-labile, designated LT, and one heat-stable, designated ST (Smith and Gyles, 1970a). During these studies, which are reported in the present paper, it was found that the enterotoxin produced by the atypical pig strains and by calf and lamb enteropathogenic strains was plasmid-controlled. So, too, was a $\mathrm{K}$ antigen possessed by the calf and lamb strains. This antigen, referred to, for convenience, as the " common $\mathrm{K}$ antigen ", was discovered by Sojka (personal communication), who had observed that many calf and lamb enteropathogenic strains, although having different $\mathrm{O}$ antigens, possessed a closely related or common $\mathrm{K}$ antigen.

Received 9 Sept. 1971; accepted 28 Sept. 1971.

* Present address: Houghton Poultry Research Station, Houghton, Huntingdon PE17 2DA, England.

J. MED. MICROBIOL.-VOL. 5 (1972) 


\section{MATERIALS AND METHODS}

Enterotoxigenic strains of Escherichia coli. The three atypical strains of $E$. coli reported by Moon and Whipp (1970) were kindly submitted by Dr Moon with the information that no. 431 and 613 had been classified serologically as $\mathrm{O} 101: \mathrm{K}$ ? and no. 637 as $\mathrm{O} 64$ : $\mathrm{K}$ ?. Our strain, $\mathbf{P} 2$, that resembled these three strains enterotoxigenically was serologically untypable. The human, calf and lamb enteropathogenic strains studied were those described previously by Smith and Halls (1967a and $b$ ).

Ligated intestinal preparations. The technique employed in calves, lambs and 8-wk-old pigs was that of Smith and Halls (1967a and $b$ ). A similar technique was employed in 3-dayold piglets except that the volume of broth culture injected into each ligated intestinal segment was $0.5 \mathrm{ml}$ instead of $1.0 \mathrm{ml}$.

Heat-stable $(S T)$ and heat-labile $(L T)$ forms of enterotoxin. These were prepared by the methods of Smith and Gyles (1970a), the volume of ST and LT employed in ligated intestine tests being 15 and $8 \mathrm{ml}$ respectively.

Transfer of ability to produce enterotoxin and common $K$ antigen. The prospective recipient strains of $E$. coli used in these studies were nalidixic acid-resistant mutants either of a $\mathrm{lac}^{-}$ strain of $\mathrm{K}^{12 \mathrm{~F}^{-}}$, an $\mathrm{O} 18: \mathrm{K}$ ? strain (F11) or an $\mathrm{O} 8: \mathrm{K}-: \mathrm{H}-$ strain (D282) kindly supplied by Dr Ida Ørskov. Transmission of the genetic elements controlling enterotoxin production was attempted by the methods described by Smith and Linggood (1971a), tests in ligated piglet intestine being employed for detecting organisms that had received them $\left(\right.$ Ent $\left.^{+}\right)$. Transmission and elimination of the common $\mathrm{K}$ antigen were attempted by the methods used by Smith and Linggood in similar studies on the K88 antigen, those organisms that had received the antigen $\left(\mathrm{Kco}^{+}\right)$and those that had lost it $\left(\mathrm{Kco}^{-}\right)$being detected by antiserum kindly provided by Mr W. J. Sojka.

Oral inoculation of E. coli. Piglets and lambs, 2 to 15 -hr-old, that had obtained colostrum, were given orally $0.5 \mathrm{ml}$ of a nutrient broth culture of the strain of $E$. coli under test after it had been incubated at $37^{\circ} \mathrm{C}$ for $24 \mathrm{hr}$. During the subsequent observation period, the animals were left with their mothers. Those that developed diarrhoea were killed and the concentrations of organisms of the infecting strain of $E$. coli in the chyme in different parts of the alimentary tract were estimated by the methods of Smith and Halls (1967a).

\section{RESULTS}

\section{Ability of strains of Escherichia coli from different sources to dilate ligated intestinal segments of pigs, calves and lambs}

The results of injecting strains of $E$. coli from different sources into ligated intestinal segments of 3-day-old piglets, 8-wk-old pigs, calves and lambs are summarised in the table.

As stated by Moon and Whipp (1970), their three strains no. 431, 631 and 637 , referred to here as atypical, consistently dilated ligated intestinal segments of the piglets but not of the pigs. So did one strain (P2) from our collection. All four strains also dilated segments of calf and lamb intestine. The typical pig-enteropathogenic strains, included for comparison, dilated segments of all four kinds of intestine examined. The calf-enteropathogenic strains, O101 (three strains), O9 (two strains), O8 (one strain) and O? (one strain) and the two lamb-enteropathogenic strains, both 08 , closely resembled the atypical pig strains in that they dilated calf, lamb and piglet intestine but not pig intestine. In contrast, the human enteropathogenic strains, O26:K60:H11 (four strains), O55:K59:H6,7 or $\mathrm{H}-$ (three strains), O128:K67:H2 or H8 (two strains), and 
O111:K58:H12 (one strain), and the 13 non-pathogenic strains, which had been isolated from the faeces of healthy piglets and calves, failed to dilate segments of any of the four kinds of intestine.

The intestinal segments of 3-day-old piglets that had been injected with the atypical pig strains, and the calf- and lamb-enteropathogenic strains were grossly distended, often containing as much as $20-30 \mathrm{ml}$ of fluid. By contrast increasing the dose of viable organisms injected to $10^{10}$ or including antibiotics to which they were resistant did not permit these strains to dilate intestinal segments of 8-wk-old pigs.

\section{TABLE}

The ability of Escherichia coli from different sources to dilate ligated intestinal segments of pigs, calves and lambs

\begin{tabular}{|c|c|c|c|c|c|}
\hline \multirow{2}{*}{ Kind of $E$. coli } & \multirow{2}{*}{$\begin{array}{l}\text { Number of } \\
\text { strains } \\
\text { examined }\end{array}$} & \multicolumn{4}{|c|}{ Reaction* in intestinal segments of } \\
\hline & & $\begin{array}{c}\text { pigs, } \\
8 \text { wk old }\end{array}$ & $\begin{array}{l}\text { piglets } \\
3 \text { days old }\end{array}$ & calves & lambs \\
\hline $\begin{array}{l}\text { Pig, typical enteropathogen } \\
\text { Pig, atypical } \\
\text { Calf, enteropathogen } \\
\text { Lamb, enteropathogen } \\
\text { Human baby, enteropathogen } \\
\text { Pig and calf, non-pathogen }\end{array}$ & $\begin{array}{r}5 \\
4 \\
7 \\
2 \\
10 \\
13\end{array}$ & $\begin{array}{l} \pm \\
\pm \\
= \\
-\end{array}$ & $\begin{array}{l}+ \\
+ \\
+ \\
+ \\
+\end{array}$ & $\begin{array}{l}+ \\
+ \\
+ \\
+ \\
-\end{array}$ & $\begin{array}{l}+ \\
+ \\
+ \\
+ \\
+\end{array}$ \\
\hline
\end{tabular}

\section{Transfer of the genetic elements controlling enterotoxin production in atypical pig strains}

The genetic elements controlling enterotoxin production were transferred during mixed culture from two of the four atypical pig strains, no. 613 and P2, to the $\mathrm{O} 8: \mathrm{K}-: \mathrm{H}-$ strain of E. coli, no. D282. Of eight colonies of D282 obtained from the mixed culture of this strain and P2, seven were found to be Ent $^{+}$. A similar proportion of D282 colonies obtained from the mixed culture of D282 and 613 were also Ent ${ }^{+}$. These D282 Ent ${ }^{+}$strains dilated ligated intestinal segments of 3-day-old piglets to the same extent as did strains P2 and 613. They failed to dilate ligated intestinal segments of 8-wk-old pigs but so usually did two D282 strains that had received Ent from one or other of two typical pig enteropathogenic strains, P19 (of antigenic structure O9:K9) and P3 (of antigenic structure O139:K82). Failure in this case was associated with inability of strain D282 to multiply adequately, or even to survive, in the ligated segments of the pigs; strains of E. coli F11 that had received Ent from strains P19 and P3 strongly dilated ligated intestinal segments of such pigs. Ent transmission was not detected during mixed culture of the four atypical pig strains and F11. 


\section{Activity of cell-free enterotoxic preparations of the atypical pig strains and calf and lamb enteropathogenic strains}

Heat-labile enterotoxin $(L T)$. LT preparations of the four atypical pig strains were tested in ligated intestinal segments of four pigs; like those of calf- and lamb-enteropathogenic strains (Smith and Gyles, 1970a), none of them caused dilatation.

Heat-stable enterotoxin $(S T)$. Twelve pigs were used for testing ST preparations of the four atypical pig strains, the seven calf- and the two lambenteropathogenic strains. In only six of them were positive reactions produced by these preparations and then only in segments in the first metre or so of the small intestine, the region most susceptible to $E$. coli enterotoxin (Smith and Halls, $1967 a$ and $b$ ). All 12 pigs were suitable for testing ST preparations of typical pig-enteropathogenic strains. In the six pigs previously referred to, ST preparations of these strains produced stronger reactions than those of the atypical pig and the calf and lamb strains. For example, the volume of fluid that accumulated in an intestinal segment injected with an ST preparation of a typical pig strain was $128 \mathrm{ml}$ whereas the volumes in two adjacent segments injected with similar preparations of two atypical pig strains were 16 and $10 \mathrm{ml}$ respectively. In another pig, the corresponding figures were $60 \mathrm{ml}$, and 11 and $9 \mathrm{ml}$; and in another, $60 \mathrm{ml}$, and 25 and $15 \mathrm{ml}$. A more accurate comparison was obtained by injecting adjacent intestinal segments with ST preparations of strains of $E$. coli D282 to which the Ent plasmid had been transmitted from the typical pig strains, P3 and P19, or the atypical ones, P2 and 613. These volumes that accumulated in six segments injected with the preparations of strain D282 that had received the plasmid from strain P3 $\left\{\right.$ D282(P3)Ent $\left.{ }^{+}\right\}$ were $60,55,45,35,30$ and $20 \mathrm{ml}$. The corresponding figures for the preparations of D282(P19)Ent ${ }^{+}$were 120,115, 10050,30 and $30 \mathrm{ml}$, for those of D282(P2) Ent $^{+}$were 15,6, 5, 5, 3 and $2 \mathrm{ml}$ and for those of D282(613)Ent ${ }^{+}$were 24, 20, 12, 6,6 and $6 \mathrm{ml}$.

The dilating activity of ST preparations of the atypical pig strains and of the calf and lamb strains, like those of typical pig strains, was not affected by antiserum or by heating at $65^{\circ} \mathrm{C}$ or $100^{\circ} \mathrm{C}$ for $15 \mathrm{~min}$., but it was markedly reduced by autoclaving for $1 \mathrm{hr}$ at $120^{\circ} \mathrm{C}$.

\section{Transfer of the genetic elements controlling common $K$ antigen production in calf and lamb enteropathogenic strains}

In mixed-culture experiments, the ability to produce the common $\mathrm{K}$ antigen, $\mathrm{Kco}$, was transferred from one of the seven calf-enteropathogenic strains, an O101 strain, to $E$. coli $\mathrm{K} 12 \mathrm{~F}^{-}$and to strain D282. It was also possible to transfer it from both of the $\mathrm{O} 8 \mathrm{lamb}$ strains to $\mathrm{D} 282$, but not to $\mathrm{K} 12 \mathrm{~F}-$. Failure to transfer to $\mathrm{K}_{12} \mathrm{~F}^{-}$was probably due to the fact that both $\mathrm{O} 8$ strains produced a powerful colicin active against this strain. Tests in ligated calf intestine revealed that all the $\mathrm{Kco}^{+}$strains of $\mathrm{K} 12 \mathrm{~F}^{-}$and $\mathrm{D} 282$ isolated in these experiments had also acquired from the $\mathrm{O} 101$ and $\mathrm{O} 8$ donor strains the ability to produce 
enterotoxin. $\mathrm{Kco}^{-}$organisms were easily obtained from the $\mathrm{Kco}^{+}$strains by treatment with acridine orange; all those tested still produced enterotoxin.

\section{Oral administration of selected strains of $E$. coli to piglets and lambs}

All except one of nine piglets given one or other of the three atypical pig strains, no. 431, 613 and 637, developed severe diarrhoea within $24 \mathrm{hr}$. Seven were killed, and abnormally high concentrations of the infecting organisms were found in the chyme in their small intestine. By contrast, all of four piglets given the fourth atypical strain, P2, remained healthy; only low concentrations of strain P2 were found in the small intestines in two of these piglets killed 2 days after oral administration. Similarly, all of ten piglets given one or other of three of the calf strains, $\mathrm{O} 101, \mathrm{O} 9$ and $\mathrm{O}$ ?, or the $\mathrm{O} 8$ lamb strains, remained healthy.

Eight lambs were given one or other of the two atypical pig strains 431 and 637; all remained healthy. So did seven lambs given one of the 08 lamb enteropathogenic strains from which the common $\mathrm{K}$ antigen had been eliminated. The numbers of the infecting organisms in the alimentary tract of two twin lambs, one of which had been given this $\mathrm{Kco}^{-}$form and the other the original $\mathrm{Kco}^{+}$form, were estimated; so were those from another lamb given the $\mathrm{Kco}^{-}$form to which the $\mathrm{K} 88$ plasmid from a typical porcine enteropathogenic strain had been transmitted. The lambs given the $\mathrm{Kco}^{-}$or the $\mathrm{Kco}^{-} 88^{+}$form had shown no sign of ill-health before they were killed, but the one given the $\mathrm{Kco}^{+}$form had developed diarrhoea some 6-12 hr previously. Very high concentrations of the infecting organisms were found in the small intestine of this lamb whereas no such abnormality was found in the other two; no organisms were isolated from the liver and spleen of these lambs.

The $\mathrm{Kco}^{-} \mathrm{K} 88^{+}$strain used in the above experiment had not only received the K88 plasmid from the typical pig-enteropathogenic donor strain but also its Ent plasmid. This was shown by the fact that it dilated ligated intestinal segments of pigs whereas its $\mathrm{Kco}^{-} \mathrm{K} 88^{-}$parent strain caused dilatation in 3-dayold piglets only.

\section{Discussion}

The results of the present investigation suggest that the enterotoxins of the atypical pig strains of Escherichia coli of Moon and Whipp (1970) and of calfand lamb-enteropathogenic strains may be identical. Furthermore, they indicate that this enterotoxin resembles the ST rather than the LT form of enterotoxin produced by typical pig-enteropathogenic strains (Smith and Gyles, $1970 a$ ) in that it was relatively heat-stable and not neutralised by antiserum. The closeness of the relationship between all these enterotoxins is further emphasised by the observation that, as in the typical pig strains (Smith and Halls, 1968), the genetic elements controlling enterotoxin production in some of the atypical pig strains and the calf and lamb strains were shown to be transmissible, presumably by Ent plasmids. The fact that ST-type preparations of $E$. coli strain D282 into which Ent plasmid of the two atypical pig strains (P2 and 613) had 
been transmitted dilated ligated intestinal segments of 8-wk-old pigs to a much lesser extent than did similar preparations of D282 into which the Ent plasmids of the two typical pig strains (P3 and P16) had been transmitted suggests that the differing effects of the typical and atypical strains on ligated intestine is largely a function of their Ent plasmids; those in the typical strains coding for greater production of ST, or a more active form of it, than those in the atypical strains. It is noteworthy in this respect that Moon and Whipp found no difference between the ability of typical and atypical pig strains to multiply in ligated pig intestine. Likewise, Smith and Halls (1967a) found that the failure of calf- and lamb-enteropathogenic strains to dilate ligated pig intestine was not due to failure to multiply. Confirmation of this and of the differing character of Ent plasmids was obtained in the present study by the finding that the O8 lamb strain, already possessing the Ent plasmid characteristic of lamb, calf and atypical pig strains, would dilate ligated intestine of pigs only after the Ent plasmid from a typical pig strain had been transmitted to it. Very occasionally, however, inability to survive or to multiply in ligated intestine can be the cause of the failure to dilate it. This had been noted by Smith and Halls (1968) in regard to an Ent ${ }^{+}$form of $E$. coli strain K12. It was again encountered in the case of strain D282, which like E. coli $\mathrm{K} 12$ is a much manipulated laboratory strain, but only in regard to the ligated intestine of pigs; the strain multiplied well in the ligated intestine of piglets, calves and lambs and, as a consequence, its $\mathrm{Ent}^{+}$forms were able to express themselves.

The failure of the human enteropathogenic strains of E. coli to dilate calf, lamb, piglet and pig intestine serves to emphasise the differences previously recorded between the enterotoxin(s) of these strains and those of calf-, lamb-, and pig-enteropathogenic strains (Smith and Halls, 1967a and $b$ ). However, LT-type preparations of many human enteropathogenic strains, like those of typical pig-enteropathogenic strains, do dilate ligated rabbit intestine (Smith and Gyles, 1970b) and in one of these human strains the genetic elements controlling enterotoxin production have been shown to be transmissible (Smith and Linggood, 1971a). These facts, together with the observation of Gyles and Barnum (1969) of an antigenic relationship between the LT form of the enterotoxin of pig E. coli and the enterotoxin of Vibrio cholerae, suggest that, although differences exist between the enterotoxins produced by the various kinds of $E$. coli and $V$. cholerae, they may all be based on the same toxic molecule.

The demonstration of its transmissibility, and the " curing " effect of acridine orange, point to common $\mathrm{K}$ antigen production in the calf- and lamb-enteropathogenic strains as yet another example of a transmissible plasmid-controlled characteristic. The designation Kco is provisionally proposed for this plasmid. Our inability to produce diarrhoea in lambs with the $\mathrm{Kco}^{-}$form of the $\mathrm{O} 8$ enteropathogenic lamb strains indicates that common $\mathrm{K}$ antigen is concerned in the pathogenic process. Since the important difference in the bacteriological picture of lambs given the $\mathrm{Kco}^{+}$and the $\mathrm{Kco}^{-}$forms of the $\mathrm{O} 8$ strain was the failure of the $\mathrm{Kco}^{-}$forms to proliferate in the small intestine-though they proliferate well in ligated intestine-it is conceivable that the common $\mathrm{K}$ antigen functions in lamb-enteropathogenic strains in the same manner as the K88 
antigen may function in some pig-enteropathogenic strains (Smith and Linggood, $1971 b$ ), by facilitating adhesion to the intestinal epithelium. If this is so, the results of the infection experiments in the present study and in a previous one (Smith and Halls, 1967a) point to the specific nature of this adhesion, the K88 antigen being unable to bring about adhesion to calf and lamb intestine and the common $\mathrm{K}$ antigen being unable to bring about adhesion to pig intestine. The infection experiments also confirmed the enteropathogenicity for piglets of the three atypical strains of Moon and Whipp. Negative results, however, were obtained with P2, the atypical strain from our collection. This strain had been isolated initially from the faeces of a healthy pig and did not belong to a serotype known to be enteropathogenic. It may be an Ent ${ }^{+}$non-pathogen, its Ent plasmid having been acquired under natural conditions.

\section{SUMMARY}

Ligated intestine tests in pigs, piglets, calves and lambs indicated that the enterotoxin produced by a group of atypical pig strains of Escherichia coli was probably identical with that produced by enteropathogenic calf and lamb strains. It resembled the ST rather than the LT form of the enterotoxin produced by typical pig enteropathogenic strains.

The enterotoxin produced by some of the atypical strains and the calf and lamb strains, like that produced by some typical pig strains, was probably controlled by a transmissible plasmid. So was a $\mathrm{K}$ antigen common to many of the calf and lamb strains. Infection experiments indicated that this antigen was important in the pathogenesis of $E$. coli diarrhoea.

We are grateful to Miss Marion White for her capable technical help. Our thanks are also due to Mr and Mrs L. A. Abbott, Dr Ida Ørskov and Dr Joan Taylor for help and assistance in various ways. The expense of this work was kindly defrayed by a grant from the Agricultural Research Council.

\section{REFERENCES}

Gyles, C. L., AND Barnum, D. A. 1967. Escherichia coli in ligated segments of pig intestine. J. Path. Bact., 94, 189.

Gyles, C. L., AND BARnum, D. A. 1969. A heat-labile enterotoxin from strains of Escherichia coli enteropathogenic for pigs. J. Infect. Dis., 120, 419.

Moon, H. W., Sorensen, D. K., ANd SAUTter, J. H. 1966. Escherichia coli infection of the ligated intestinal loop of the newborn pig. Amer. J. Vet. Res., 27, 1317.

Moon, H. W., AND WHIPP, S. C. 1970. Development of resistance with age by swine intestine to effects of enteropathogenic Escherichia coli. J. Infect. Dis., 122, 220.

Nielsen, N. O., AND SAUtTer, J. H. 1968. Infection of ligated intestinal loops with haemolytic Escherichia coli in the pig. Canad. Vet. J., 9, 90.

SMITH, H. W., AND Gyles, C. L. 1970a. The relationship between two apparently different enterotoxins produced by enteropathogenic strains of Escherichia coli of porcine origin. J. Med. Microbiol., 3, 387.

Smith, H. W., AND Gyles, C. L. 1970b. The effect of cell-free fluids prepared from cultures of human and animal enteropathogenic strains of Escherichia coli on ligated intestinal segments of rabbits and pigs. J. Med. Microbiol., 3, 403.

Smith, H. W., ANd Halls, Sheila 1967a. Observations by the ligated intestinal segment and oral inoculation methods on Escherichia coli infections in pigs, calves, lambs and rabbits. J. Path. Bact., 93, 499. 
Smith, H. W., and Halls, SheIla 1967b. Studies on Escherichia coli enterotoxin. J. Path. Bact., 93, 531.

Smith, H. W., AND Halls, Sheila 1968. The transmissible nature of the genetic factor in Escherichia coli that controls enterotoxin production. J. Gen. Microbiol., 52, 319.

SMITH, H. W., AND LINGGOOD, MARGARET A. 1971a. The transmissible nature of enterotoxin production in a human enteropathogenic strain of Escherichia coli. J.Med. Microbiol., 4,301 .

Smith, H. W., AND LINGgood, Margaret A. 1971b. Observations on the pathogenic properties of the K88, Hly and Ent plasmids of Escherichia coli with particular reference to porcine diarrhoea. J. Med. Microbiol., 4, 467. 